\title{
Insights into functional polymer-based organic-inorganic nanocomposites as leather finishes
}

\author{
Qianqian Fan ${ }^{1,2}$, Jianzhong $\mathrm{Ma}^{1,2^{*}}$ and Qunna $\mathrm{Xu}^{1,2^{*}}$
}

\begin{abstract}
Nowadays, the increasing demands from consumer challenges the traditional leather products. Traditional polymer leather finishes gradually lose their dominant position in the market. To address this issue, recent research effort has been devoted to developing polymer-based organic-inorganic nanocomposite leather finishes due to their various functional properties including antibacterial, self-cleaning and water-resistant property. In this review, we provide a comprehensive overview of synthesis of polymer-based organic-inorganic nanocomposites and their application as functional leather finishes. With the perspective of their properties and current challenges, an outlook in the future development about crafting functional and high-quality leather finishes are further proposed.
\end{abstract}

Keywords: Organic-inorganic nanocomposites, Polymer, Functional leather finishes

\section{Introduction}

In leather industry, crafting coatings on leather surface is known as finishes. In this process, binders, pigments, auxiliaries, etc. are applied onto the surface of leather. Finishing has been recognized as one of the most essential processes in leather making industry, moreover, finishing agents could not only beautify leather appearance, but also render leather good mechanical properties in a simple way [1-5]. Nowadays, the increasing demands from consumer challenges the traditional leather products. Therefore, functional finishing agent has sparked strong interests in leather industry. In daily life, the long-term contact of clothes (for example, garment leather) with human body may result in a rapid growth of bacteria and fungi, thus greatly reducing the value of leather product [6]. To solve this problem, antibacterial coatings have been crafted on leather surface.

To date, a set of functional properties, such as selfcleaning, water-resistant, antibacterial properties, and so on, has been obtained via finishing technology on leather surfaces [7-13]. Generally, finishing agents are composed of polymers, which possess good film-forming

\footnotetext{
* Correspondence: majz@sust.edu.cn; xxqqnn870304@163.com ${ }^{1}$ College of Bioresources Chemical and Materials Engineering, Shaanxi University of Science and Technology, Xi'an 710021, China Full list of author information is available at the end of the article
}

properties. Among organic components, polyacrylates, polyurethane (PU) and casein have attracted much attention due to their special behavior as film-formers [4, 14-19]. However, pristine polymer binders only exhibit basic performance (e.g., adhesive property), which cannot meet the increasing demand of markets. As reported, inorganic units, especially several nanoparticles are responsible for outstanding thermal stability, mechanical properties, and other functions. Thus, combination of the polymer binder and inorganic nanoparticles together may be a good choice to acquire a set of intriguing functions. Therefore, exploration for functional organic-inorganic nanocomposite finishing agents is indeed necessary.

Organic-inorganic nanocomposites possess the advantages of organic and inorganic constituents to achieve excellent properties [20-24]. In leather processing, nanocomposite was firstly employed as tanning agents, while the report about its application in leather finishing was found started in the early twenty-first century [25]. They incorporated nano $\mathrm{TiO}_{2}$ into polyacrlate emulsion, and then applied the composite emulsion on leather surface, which proved that mechanical and hygiene property of the finished leather are both enhanced. Since then, studies on organic-inorganic nanocomposite leather finishes have been gradually released. Nano $\mathrm{SiO}_{2}$, 
$\mathrm{TiO}_{2}$, graphene oxide, etc. have been introduced into various polymer matrixes via different methods, thus functionalizing leather surfaces.

In 2006, nano- $\mathrm{SiO}_{2}$ /acrylic resin nanocomposite was fabricated as leather finishes via in situ method in our group [26]. Compared with leather sample finished with acrylic resin, water-vapor permeability and air permeability of nanocomposite finished leather were increased by $7.42 \%$ and $7.33 \%$, respectively. Furthermore, dry-wet rub fastness of the nanocomposite finished leather was raised by 1 grade, which resulted from the presence of inorganic phase to large extent, of course, superior distribution of inorganic nanoparticles in polymer matrix was of great importance. Up to now, in our group, fabrication and application of organic-inorganic nanocomposite leather finishes have been conducted for more than 10 years. For example, silica, $\mathrm{TiO}_{2}$ and $\mathrm{ZnO}$ nanoparticles have been separately introduced into polyacrylate or casein matrix via various methods for leather finishing. Film-forming models and inter-facial interaction mechanism of the composite leather finishes were also established which may be of great significance for further study [27-29]. This review mainly gives an overview of synthesis of these polymer-based organic-inorganic nanocomposites and their application as functional leather finishes. Accordingly, research outlooks in this aspect are proposed.

\section{Synthesis of polymer-based organic-inorganic nanocomposites}

Since nanocomposites have attracted more and more interests, various routes are designed to engineer materials, for example, to integrate the superiority of nanoparticles and polymers. The integration of polymer matrix with inorganic nanoparticles can be carried out in many ways, which were summarized in the following.

\subsection{Sol-gel processing}

Sol-gel processing is recognized as the first method in fabrication of polymer-based organic-inorganic nanocomposites, which has been explored for more than two decades $[30,31]$. Interpenetrating networks between inorganic and organic phases can be observed in the nanocomposite prepared by sol-gel processing, which endow nanocomposites with good compatibility. Epoxy resin $/ \mathrm{SiO}_{2}$ hybrid coatings were fabricated through photo-polymerization, where $\mathrm{SiO}_{2}$ nanoparticles were generated via sol-gel process [32]. Good compatibility between the organic and inorganic units can be confirmed by atomic force microscope (AFM) measurement (Fig. 1). Functionalized graphene/PU nanocomposite coatings were prepared via sol-gel method [33]. Organosilanes were used for the functionalization of graphene. Addition of the functionalized graphene in PU coatings promises improved mechanical and thermal properties, which was mainly attributed to the welldispersed graphene in polymer matrix.

In our previous study, acrylic resin/ $/ \mathrm{SiO}_{2}$ nanocomposite was prepared by integrating nano- $\mathrm{SiO}_{2}$ sol gel with acrylic resin [34]. Results indicated that incorporation of nano- $\mathrm{SiO}_{2}$ sol gel into acrylic resin matrix facilitates the compatibility between two phases, thus further improving the stability and water resistance of the as-prepared composite coating.

\subsection{Blending}

Combining nanoparticles with polymer matrix to form nanocomposites has been explored for decades, while

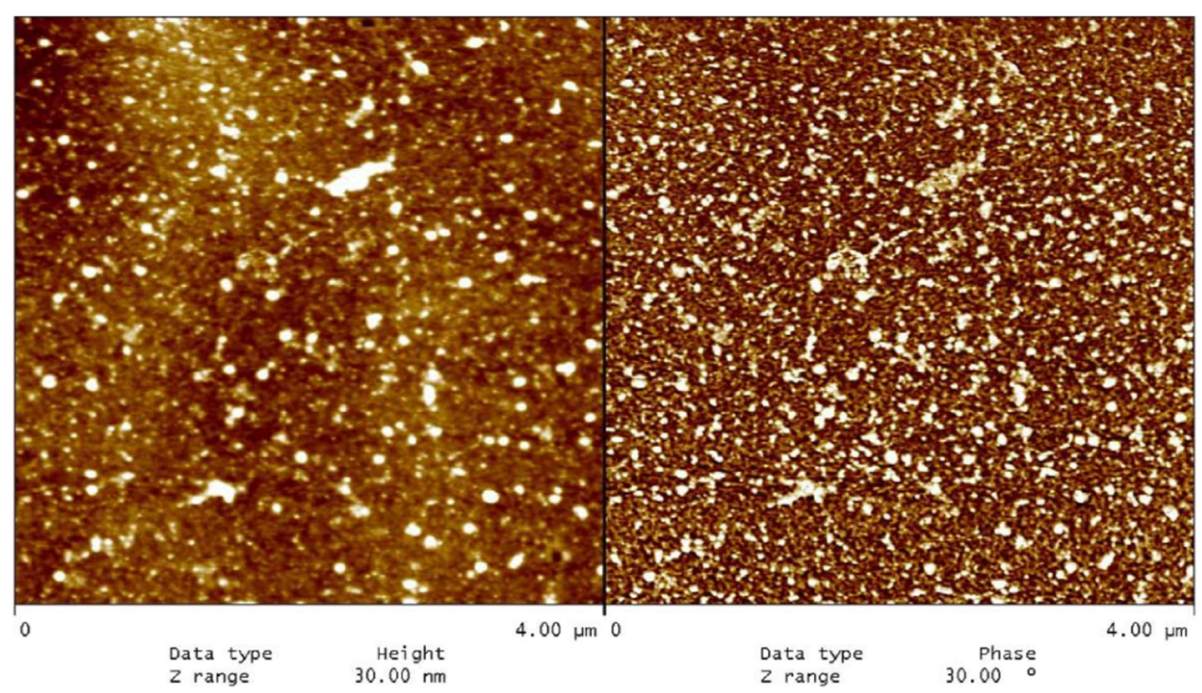

Fig. 1 AFM topography (left panel) and phase contrast image (right panel) for the functionalized graphene/PU hybrid coatings containing 50\% TEOS[32]. Copyright 2005, Elsevier 
blending is recognized as the most facile and direct approach [35]. Blending can be accomplished by several ways, including mechanical blending, melt blending, solution blending or emulsion blending, which mainly depends on the nature of polymer [36-38]. Nowadays, blending method has been extensively employed in the industry by relatively wider acceptance of inorganic particles with various shapes, sizes, or characters [35]. As for melt blending, although it can be done rapidly with facile polymer extrusion processes, it has been rarely used for water-based system. Regarding economic and environmental limitation, solvent-based processes were not accepted to produce composite materials. Of course, it is not suitable for leather finishing. Therefore, waterbased emulsion blending holds much promise in fabricating polymer-based organic-inorganic nanocomposite for leather finishes.

Graphene has attracted extensive scientific interest due to its excellent physical properties. Waterborne polyurethane (WPU)/grapheme oxide (GO) complex leather finishes were prepared by mixing WPU and GO under ultrasonic treatment (Fig. 2) [39]. The results indicated that adding sodium dodecyl sulfate could improve the dispersion of GO nanosheets in WPU. To further improve the dispersion of GO in polymer emulsion, GO was modified by carboxylation with bromoacetic acid [40]. Results indicated that such hydrophilic modification of GO helped improve its dispersion in polymer emulsion. In addition, acrylic resin/nano $\mathrm{TiO}_{2}$ nanocomposite was obtained by blending, where it was found that sodium hexametaphosphate can be used as a dispersing agent to reduce surface energy of nanoparticles, thus giving well-dispersion of nano $\mathrm{TiO}_{2}$ in acrylic resin [41].

In our group, a series of functional nanocomposites has been developed via emulsion blending. Meanwhile, different shaped nanoparticles were fabricated and blended with polyacrylate, PU or casein emulsion. It's found that surface modification of nanoparticles can facilitate their well-dispersion in polymer matrix. For example, we prepared amino-functionalized graphene oxide (NGO) and blended it with polyacrylate emulsion. As is known, amino group is hydrophilic, so it can help the dispersion of NGO in aqueous solution or latex. Results showed that polyacrylate based NGO composite leather finishes exhibited enhanced thermal stability [42].

\subsection{In situ method}

In situ method has been adopted as the most efficient way to produce nanocomposite with good stability, in which nanoparticles are well-dispersed in polymer matrix. There are three common ways to obtain nanocomposite via in situ method: 1) in situ growth of nanoparticles in polymer matrix; 2) in situ polymerization of polymer in the presence of pre-formed nanoparticles; 3 ) double in situ method, consisting of the simultaneous generation of polymer matrix and nanoparticles, as described in the following.

\subsubsection{In situ growth of nanoparticles in polymer matrix}

In this method, nanoparticles are generated from precursors, while polymer matrix is pre-formed. In situ preparation of nanoparticles can be conducted by various ways, including acid/alkali-induced hydrolysis, chemical reductions, and photo-reductions. Goyal, et al. demonstrated a one-step approach for crafting polydimethylsiloxane (PDMS)/noble metal nanoparticle composite films [43]. Metal salts (Ag, $\mathrm{Au}$ and $\mathrm{Pt}$ ), silicone elastomer, and the hardener (curing agent) were mixed to form a homogenous mixture. Then coatings were crafted by curing. In curing process, the hardener plays double roles: crosslinking the elastomer and reducing metal salts to produce nanoparticles. In this study, reducing or stabilizing agent was avoided, meanwhile, an even distribution of nanoparticles in PDMS film was observed. In Lu's group, in-situ growth of Ag nanoparticles on polydopamine (PDA)-functionalized silk was achieved via a facile and green approach [44]. Ag nanoparticles were deposited evenly on the surface of fiber, where PDA was used as reduction agent.

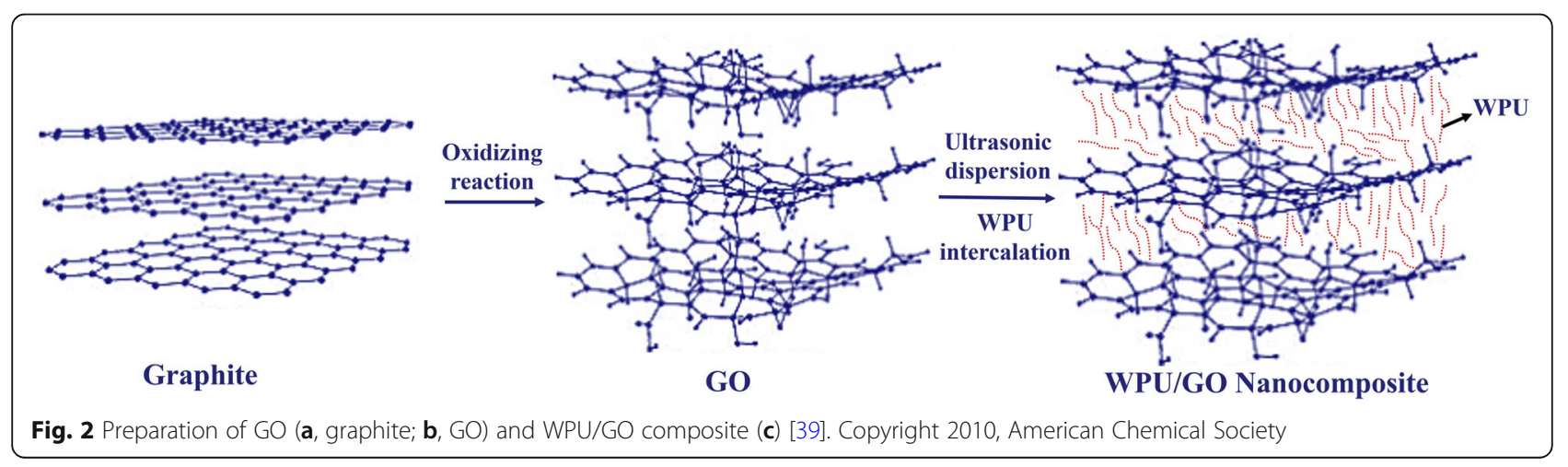




\subsubsection{In situ polymerization of polymer in the presence of nanoparticles}

Alternately, polymerization of monomers can be conducted around the pre-formed nanoparticles to obtain hybrid materials. In this method, inorganic nanoparticles are first dispersed in monomers, and then polymerization of monomers is processed. Homogeneous dispersion of nanoparticles can be acquired in this method due to low viscosity of monomers. Poly(methyl methacrylate) $/ \mathrm{CaCO}_{3}$ nanocomposites were obtained by in situ method [45]. Stearic acid capped $\mathrm{CaCO}_{3}$ nanoparticles $(\sim 40 \mathrm{~nm})$ were used as fillers. The presence of stearic acid renders $\mathrm{CaCO}_{3}$ nanoparticles with hydrophobic properties, thus rendering it good compatibility with polymer matrix. Carbon nanotubes $(\mathrm{CNT}) /$ polymer composite films were prepared via in-situ bulk polymerization method [46]. CNT array was infiltrated with styrene monomer to prevent CNT aggregation, where polystyrene-polybutadiene copolymer was used as a plasticizer. In our group, inorganic/organic nanocomposites were fabricated utilizing synthetic or natural polymer matrix via in situ method. For example, caprolactam-casein/ZnO nanocomposite was prepared by in situ method, where commercially available $\mathrm{ZnO}$ nanoparticles were introduced during the condensation polymerization of caprolactam-casein [27]. Transmission electron microscopy measurements revealed that $\mathrm{ZnO}$ nanoperticles were incorporated in the casein micelles. Polyacrylate/ZnO nanocomposite was also crafted by this in situ method. In detail, a set of nanostructural $\mathrm{ZnO}$ particles have been separately introduced into polyacrylate emulsion [47]. It was noted that most of $\mathrm{ZnO}$ nanoparticles could be dispersed uniformly in polyacrylate emulsion, while flower-like $\mathrm{ZnO}$ nanoparticles exhibited their inhomogeneity in the composite emulsion.

Another approach, so called double in situ method, has been developed, in which the generation of polymer and nanoparticles was carried out at the same time. It has been accepted as the most efficient method for synthesis of polymer-based organic-inorganic nanocomposites with good stability. MgAl layered double hydroxide (LDH) was added in poly(methyl methacrylate) matrix by Chen, et al. via double in situ method [48]. The width of as-prepared $\mathrm{MgAl} \mathrm{LDHs}$ is $60-120 \mathrm{~nm}$ and thickness is $25-40 \mathrm{~nm}$, which could be dispersed evenly in PMMA matrix. In our previous work, casein-based silica nanocomposite emulsion was fabricated via double in situ method [29]. Compared with the control system (single in situ polymerization), silica nanoparticles were dispersed uniformly in the outer layer of the resultant nanocomposite films. Furthermore, polyacrylate/ $/ \mathrm{TiO}_{2}$ nanocomposite was prepared via double in situ polymerization [49]. Results revealed that $\mathrm{TiO}_{2}$ particles were mainly dispersed on the outer layer of latex particles.
As described above, polymer-based organic-inorganic nanocomposites have been developed by sol-gel processing, blending, and in situ method. However, stability of the as-synthesized nanocomposites still needs to be improved, and distribution of inorganic nanoparticles in polymer matrix is difficult to be tunable, when precipitates are easily found during transportation or storage before use. Nevertheless, only uniform dispersion of inorganic nanoparticles in polymer matrix can promise the desired functional composite leather finishes. Notably, nanocomposites obtained by double in situ method showed improved stability. In this approach, in situ formation of nanoparticles during the polymerization of monomers facilitates the $\mathrm{H}$-bond formation between inorganic and organic phases, thus giving good stability of resultant nanocomposite. Therefore, double in situ method holds much promise in preparing functional composite leather finishes both in the fundamental and industrial view.

\section{Application of polymer-based organic-inorganic nanocomposites as functional leather finishes}

\subsection{Antibacterial leather finishes}

As mentioned above, the long-term contact of clothes (for example, garment leather) with human body may result in a rapid growth of bacteria and fungi, thus affecting the wear feeling. In Gaidau's research, $\mathrm{Ag}-\mathrm{TiO}_{2}$ and $\mathrm{Ag}-\mathrm{N}-\mathrm{TiO}_{2}$ nanoparticles were embedded in binders and applied in leather finishing [50]. The finished leather exhibited excellent antibacterial and self-cleaning behaviors under visible light irradiation. Additionally, in our group, polyacrylate-based $\mathrm{ZnO}$ nanocomposite was prepared, where PA30, an anionic polymer, was employed to modify $\mathrm{ZnO}$ [51]. Capping PA30 on $\mathrm{ZnO}$ surface endowed the finished leather with improved antimicrobial behaviors. In addition, $\mathrm{ZnO}$ nanoparticles with different structures were incorporated into polyacrylate binder [52]. The composite emulsion containing hollow columnarlike $\mathrm{ZnO}$ was applied on leather surface, and the results revealed that finished leather showed improved hygienic and antibacterial behaviors. To investigate the effect of $\mathrm{ZnO}$ nanoparticle structure on the performance of composite, different structural $\mathrm{ZnO}$ nanoparticles have been incorporated into polyacrylate emulsion [47]. Results indicated that addition of sphere-like $\mathrm{ZnO}$ and flower-like $\mathrm{ZnO}$ nanoparticles could endowed the composite films with enhanced antibacterial properties. By incorporating flower-like $\mathrm{ZnO}$ nanoparticles, water vapor permeability of the resultant film was boosted by $122.17 \%$. Conversely, the addition of sphere-like $\mathrm{ZnO}$ nanoparticles in polyacrylate film is beneficial for enhancing it mechanical properties. Polyacrylate-based $\mathrm{TiO}_{2}$ composite emulsion was also synthesized via double in situ method. Antibacterial properties and thermal stability of the polyacrylate 
film was improved by incorporating nano $\mathrm{TiO}_{2}$ [48]. As is known, casein, a natural protein, is sensitive to bacteria. In our recent work, casein-based $\mathrm{ZnO}$ nanocomposite was prepared by in situ method to solve this problem [27]. $\mathrm{ZnO}$ nanoparticles could be found on the surface and cross-section of casein-based composite film through scanning electron microscope images. Moreover, the asprepared films exhibited outstanding antibacterial ability against Escherichia coli and S. aureus, as shown in Fig. 3.

\subsection{Water resistant leather finishes}

It is well known that there are abundant hydrophilic groups in collagen-based materials, such as $-\mathrm{NH}_{2}$, $-\mathrm{COOH}$ and $-\mathrm{OH}$, so leather can be called a naturally hydrophilic material. Leather products can be easily attacked by water or bacteria. If the leather product is water resistant, the above issues can be avoided. $\mathrm{Cu}$ nanoparticles have been added into commonly used leather finishing agent, and then applied in leather finishing [3]. Leather finishing agent containing $\mathrm{Cu}$ nanoparticles was sprayed on the base and top layer. Notably, addition of $\mathrm{Cu}$ nanoparticles could endow leather with good wet and rub fastness, and color fastness to water due to the relative hydrophobicity of $\mathrm{Cu}$ nanoparticles (compared to other finishing ingredients).

In our group, acrylic resin-based $\mathrm{SiO}_{2}$ leather finishing agent crafted by emulsifier-free emulsion polymerization was used in leather finishing [53]. Water uptake rate of leather finished by nanocomposite was increased by $17.89 \%$. In another work, acrylic resin-based $\mathrm{SiO}_{2}$ composite obtained by blending acrylic resin with nano $\mathrm{SiO}_{2}$ sol-gel was applied in leather finishing [42]. Water resistance and solvent resistance of as-prepared composite finished leather were improved by $55.94 \%$ and $54.79 \%$, respectively, compared with those of acrylic resin finished leather. Similar results can be found in polyacrylate-based nano $\mathrm{SiO}_{2}$ composites [54]. In the study of polyacrylatebased nano $\mathrm{SiO}_{2}$ composite leather finishes [55], it was observed that water resistance and mechanical properties of the composite film were improved in the presence of lauryl methacrylate. Additionally, in 2015, a facile layer-by layer (LBL) spraying method was employed in our group to craft superhydrophobic coatings on leather surfaces [56]. The coating was crafted by simply spraying polyacrylate emulsion and hydrophobic silica nanoparticles on leather surface, as depicted in Fig. 4. The hydrophobicity of coated leather surface could be tuned by controlling spraying layers of $\mathrm{SiO}_{2}$ nanoparticles. This spraying method can also be used for fabricating superhydrophobic coatings on other substrates. Notably, re-spraying of hydrophobic $\mathrm{SiO}_{2}$ dispersion can restore cracks or scratches on the coated leather surface. This method was simple to operate and cost-effective, thus holding much promise for practical applications.

\subsection{Self-cleaning leather finishes}

In daily life, garment surface is easily attacked by dirt. Unlike clothes made of other materials, leather garments cannot be washed directly. To address this issue, intelligent surface has been developed to modify leather surfaces. Recently, crafting self-cleaning coatings on leather surface has been explored. In this field, the commonly used method is to produce superhydrophilic coatings that prevent stains touch. As is known, intrinsic hydrophilicity and singular photocatalytic ability of $\mathrm{TiO}_{2}$ make it a good candidate for fabricating superhydrophilic selfcleaning coatings. In Petica's work, $\mathrm{TiO}_{2}$ nanoparticles $\left(\mathrm{TiO}_{2} \mathrm{NPs}\right)$ doped with $\mathrm{N}$ and $\mathrm{Fe}$ were prepared. The obtained NPs exhibited improved photocatalytic activity under visible light [57]. Doped $\mathrm{TiO}_{2} \mathrm{NPs}$ were embedded in acrylic binder, and then used in leather finishing. Leather finished with Fe-N co-doped $\mathrm{TiO}_{2} \mathrm{NPs}$ showed obvious degradation behavior for methylene blue (MB) under visible light irradiation. After $30 \mathrm{~h}$ of exposure to visible light, $\mathrm{MB}$ spots and ball pen ink lines on the leather surface were almost invisible. Water contact

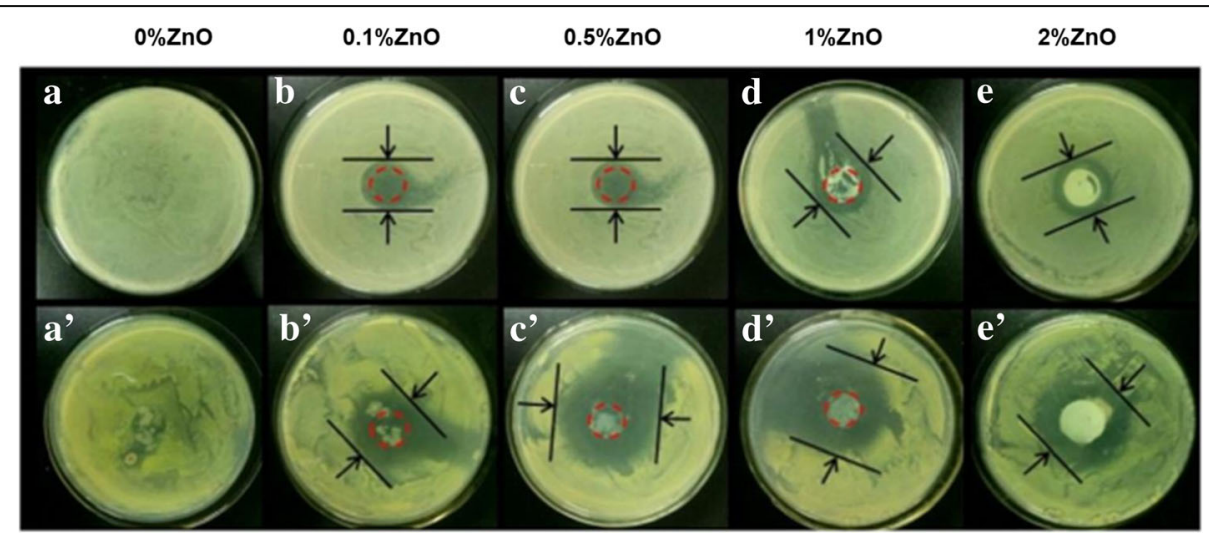

Fig. 3 Antibacterial property of caprolactam-casein (a, a') and caprolactam-casein/ZnO (b-e, b'-e') nanocomposites against (a-e) E.coli and (a'-e') S. aureus [27]. Copyright 2017, Elsevier 


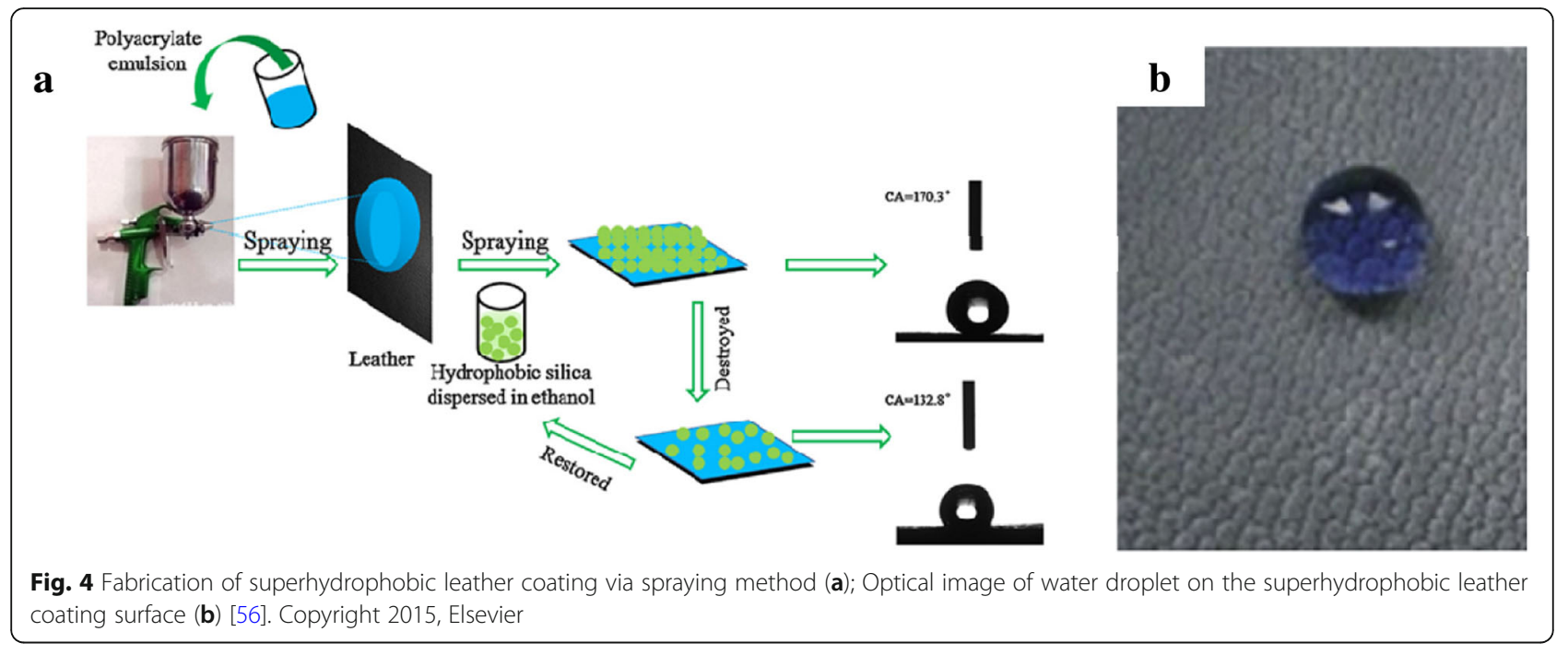

angle tests confirmed that photo-induced hydrophilicity process was mainly responsible for the degradation phenomena on leather surface. In addition, silica doped $\mathrm{TiO}_{2}$ NPs were also used for leather finishing [58]. Leather finished with the composites demonstrated obvious photocatalytic properties against MB under UV and visible light exposure due to the hydrophilicity of leather surface.

In our study, casein, polyacrylate and commercially available $\mathrm{TiO}_{2}$ NPs was integrated to obtain caseinbased $\mathrm{TiO}_{2}$ nanocomposite via single in-situ method [29]. Significantly, the composite film exhibited efficient self-cleaning ability to stains including coffee, red wine, dye, and oil, which shows its potential application as functional coatings on various substrates. Figure 5 shows the results of discoloration of coffee stains on nanocomposite treated fabric under UV irradiation. It is noted that composite treated fabrics exhibited obvious color degradation under UV irritation. Degradation of coffee stains is attributed to the oxidative degradation induced by generated active radicals from $\mathrm{TiO}_{2}$. Accordingly, schematic illustration of the self-cleaning behavior has been demonstrated in Fig. 6. Under UV irradiation, electron-hole pairs can be generated from $\mathrm{TiO}_{2}$ and transfer to the fabric surface. Subsequently, the generated hole reacts with adsorbed water or hydroxyl ion, thus producing hydroxyl radicals. These hydroxyl radicals have been recognized as the strongest oxidant, which is responsible for the photocatalytic decomposition of organic stains. Coffee stains on the casein-based $\mathrm{TiO}_{2}$ nanocomposite treated fabric were decomposed under the photocatalytic action of hydroxyl radicals. Thus, obvious stain discoloration could be observed on the fabric surface.

\subsection{Other functional leather finishes}

Besides the functional leather finishes described above, other functional finishes are on exploring to endow leather products with continuous performance, such as, high water vapor permeability, yellowing resistance, fragrance/mildew preventive sustained releasing property, etc., which will better meet the requirement of consumers and market.

To enhance water vapor permeability of finished leather, hollow silica spheres were blended with polymer binder, and then applied on leather surface $[59,60]$. The results showed that hollow size and shell thickness of hollow silica spheres were much important for the improvement of water vapor permeability of finished leather. The presence of hollow silica spheres could

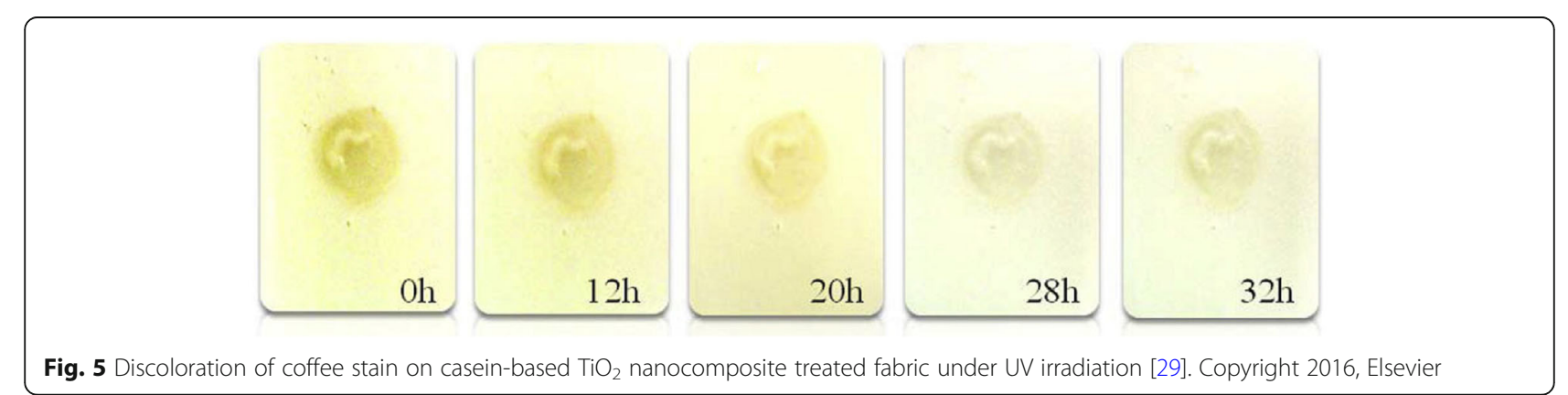



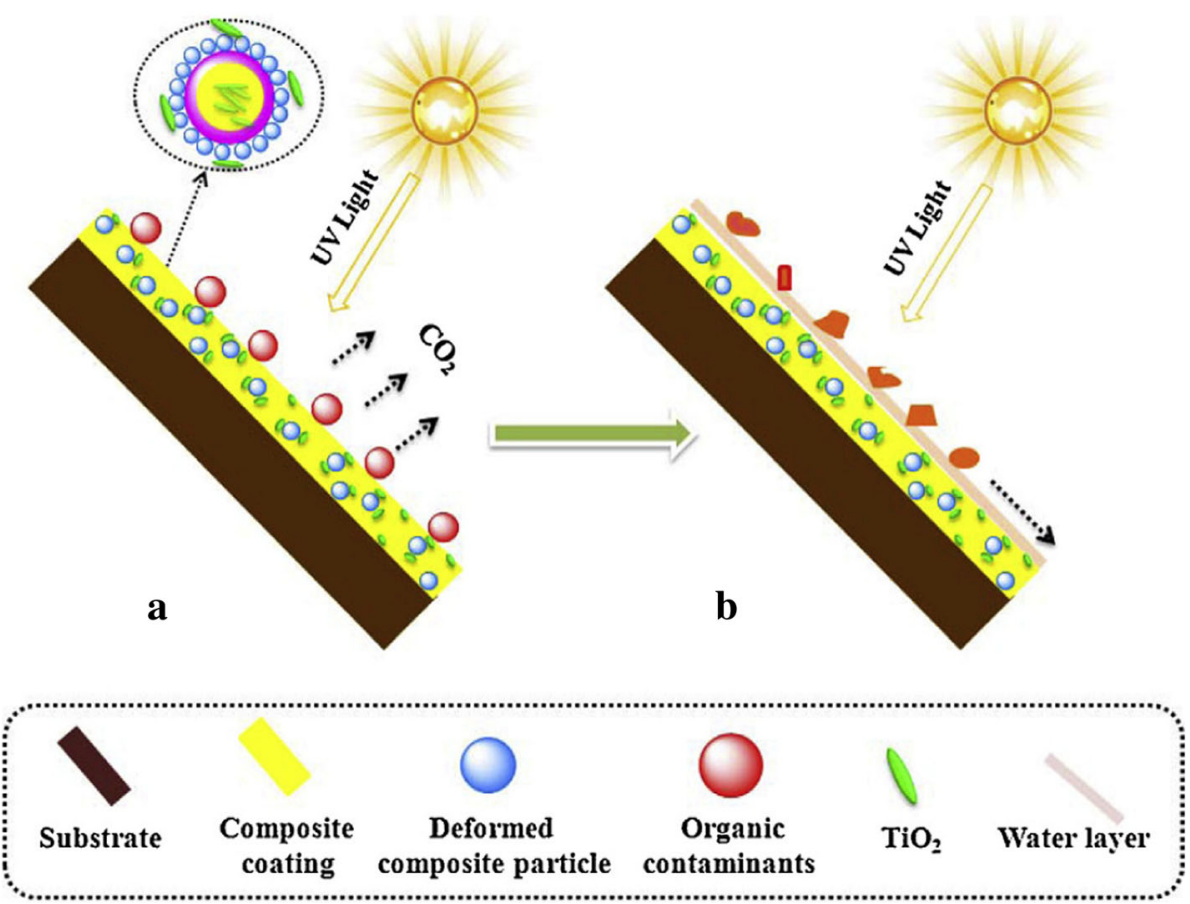

Fig. 6 Schematic illustration of the self-cleaning behavior of casein-based $\mathrm{TiO}_{2}$ composite coatings in the initial (a) and intermediate (b) stage [29]. Copyright 2016, Elsevier

provide more free volume for the composite film, so water vapor permeability was improved. Furthermore, to restraint yellowing of leather products, especially for the one with light color, polyacrylate/ZnO nanocomposite was employed as leather finishes since $\mathrm{ZnO}$ nanoparticles can absorbed ultraviolet light, thus reducing the effect of ultraviolet light on polymeric coating and leather itself [61]. In our recent research, chitosan-coated silica nanocapsules with a double-shelled structure were added into casein binder as leather finishes (Fig. 7) [62, 63]. The finished leather showed sustained fragrance release behaviors. Meanwhile, casein-based silica hollow spheres were used as carrier for mildew preventive, and then applied on leather surface to endow leather with long-term
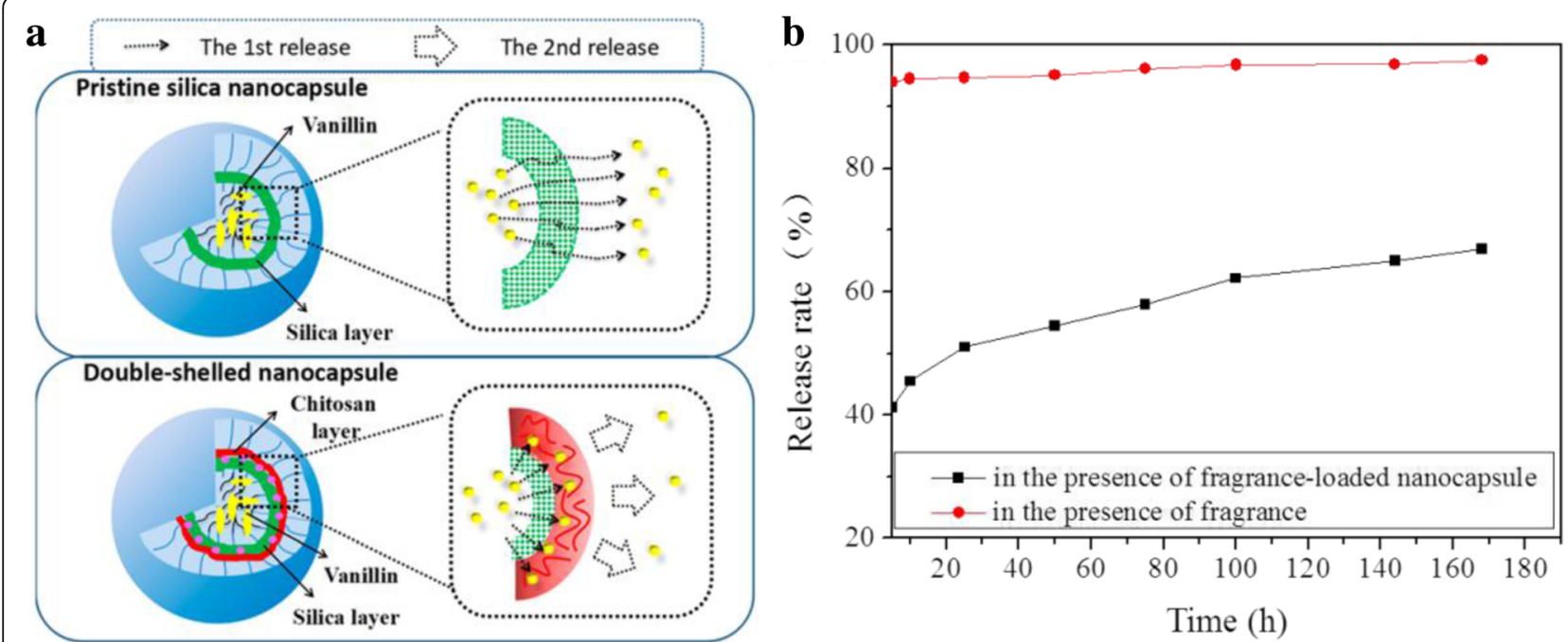

Fig. 7 Scheme of vanillin release from pristine silica capsule and double-shelled nanocapsule (a); Vanillin release rate of the leather samples finished by vanillin-loaded chitosan-based silica nanocapsules (red line) and vanillin (black line) (b) [62, 63]. Copyright 2018, American Chemical Society 
mildew resistance [64]. However, encapsulation approaches often results in high cost and complicated operations. Accordingly, a facile LBL spraying method was employed to crafting sustained aromatic coatings separately in our recent work [65]. In the coating process (Fig. 8), polyacrylate emulsion was firstly sprayed on the substrate as base layer. Next, vanillin, and commercially available $\mathrm{SiO}_{2}$ NPs were sprayed separately, then covered by chitosan. In this study, fragrance was covered by $\mathrm{SiO}_{2}$ and chitosan layer that hinder its rapid diffusion. This LBL spraying method holds much promise in fabrication of functional leather finishes due to its simple operation.

\section{Conclusion and outlook}

Up to now, great efforts have been made to organicinorganic nanocomposite, which show unique performance for functional leather finishes. However, there are relatively less researches on functional organic-inorganic nanocomposite-based leather finishes, especially in leather industry. Meanwhile, several issues listed in the following still need to be further addressed.

Firstly, stability of organic-inorganic nanocomposite is much important for giving expected performance. However, aggregation of inorganic nanoparticles in waterbased polymer binder is still found during storage or transportation before use in industry. Solutions to this problem can not only be focused on hydrophilic treatment on the surface of nanoparticles, but also on searching novel synthesis method to obtain nanocomposite with better compatibility between inorganic and organic phases. Furthermore, deep and systematical study on the interface interactions between different phases should also be paid much attention.

Secondly, selections of polymer or nanoparticles are limited based on recent research advance, which are not conducive to obtain leather finishes with diverse functions. As is known, different nanoparticles show different properties. Therefore, other inorganic particles or polymer binder should be explored. For example, in the case of polymer binder, chitosan, zein or other natural polymers should be tried to develop green leather finishes. For inorganic particles, quantum dot material can be chosen to fabricate novel finishing agent, thus giving leather products with singular property.

Finally, effects of the microstructure of nanocomposite on performance of finished leather are not indepth, further studies should be carried out on this part. As leather is derived from natural product, the effects on the performance of finished leather may be complicated. Advanced characterization technologies should be tried a lot to investigate the microstructure changes of leather surfaces before and after finishing. Meanwhile, computer modeling technique can also be used to explore the interface interactions between nanocomposite and leather surface, which may facilitate to reveal relationship between the microstructure of nanocomposite and performance of finished leather.

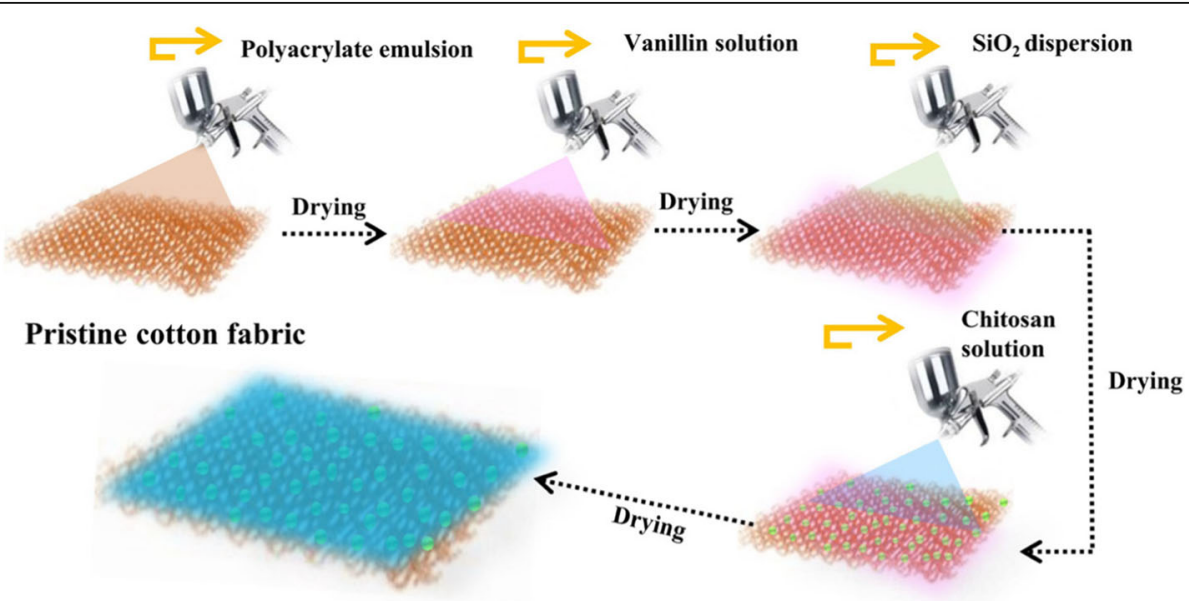

Multifunctional coated cotton fabric

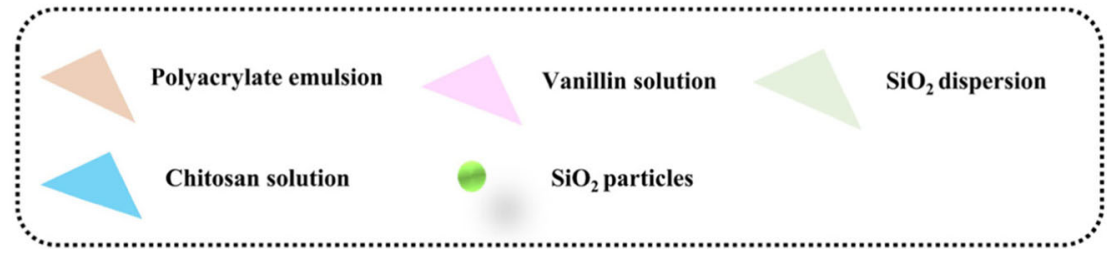

Fig. 8 Illustration for fabrication of the sustained aromatic coatings on cotton fabrics [65]. Copyright 2018, Elsevier 
In our further researches, high-quality and robust leather finishes will be investigated with an emphasis on multifunctional inorganic/organic nanocomposites. More facile and versatile approaches, as well as future applications of nanocomposites materials will be developed from both fundamental and practical viewpoints.

\section{Acknowledgments}

This work was supported by the National Key Research and Development Program of China (2017YFB0308602), Key Scientific Research Group of Shaanxi province (2013KCT-08), Young Talent Lifts Planning Project of Shaanxi Provicial University Science Association (20180416), and Scientific Research Innovation Team Building Project of Shaanxi University of Science and Technology (TD12-03).

\section{Funding}

National Key Research and Development Program of China

(2017YFB0308602);

Key Scientific Research Group of Shaanxi province (2013KCT-08);

Young Talent Lifts Planning Project of Shaanxi Provicial University Science Association (20180416);

Scientific Research Innovation Team Building Project of Shaanxi University of Science and Technology (TD12-03).

\section{Availability of data and materials}

Available.

\section{Authors' contributions}

QF---Writing this review article, summarizing the literatures; JM---Designing the outline of this article, revising the draft; QX---Revising the draft, mainly focus on the language and logicality. All authors read and approved the final manuscript.

\section{Competing interests}

The authors declare that they have no competing interests.

\section{Publisher's Note}

Springer Nature remains neutral with regard to jurisdictional claims in published maps and institutional affiliations.

\section{Author details}

${ }^{1}$ College of Bioresources Chemical and Materials Engineering, Shaanx University of Science and Technology, Xi'an 710021, China. ${ }^{2}$ Key Laboratory of Leather Cleaner Production, China National Light Industry, Xi'an 710021, China.

Received: 30 January 2019 Accepted: 4 April 2019

Published online: 29 July 2019

\section{References}

1. Mohamed OA, Moustafa AB, Mehawed MA, El-Sayed NH. Styrene and butyl methacrylate copolymers and their application in leather finishing. J Appl Polym Sci. 2009;111:1488-95

2. Fan Q, Ma J, Xu Q, Zhang J, Simion D, Carmen G, Guo C. Animal-derived natural products review: focus on novel modifications and applications. Colloids Surf B. 2015:128:181-90.

3. Kothandam R, Pandurangan M, Jayavel R, Gupta S. A novel nano-finish formulation for enhancing performance properties in leather finishing applications. J Clust Sci. 2016;27:1263-72.

4. Ma J, Xu Q, Zhou J, Gao D, Zhang J, Chen L. Nano-scale core-shell structural casein based coating latex: synthesis, characterization and its biodegradability. Prog Org Coat. 2013;76:1346-55.

5. Sundara S, Vijayalakshmia N, Guptab S, Rajaramc R, Radhakrishnan G Aqueous dispersions of polyurethane-polyvinyl pyridine cationomers and their application as binder in base coat for leather finishing. Prog Org Coat. 2006;56:178-84.

6. Fernandes IP, Amaral JS, Pinto V. Development of chitosan-based antimicrobial leather coatings. Carbohydr Polym. 2013;98:1229-35.
7. Fang $L$, Honglei $Y$, Shulu M. Antibacterial activity of chitosan-metal ion complexes in leather top-finishing. China Leather. 2009;38:9-12 (in Chinese)

8. Xiang J, Ma L, Su H, Xiong J, Li K., Xia Q, Liu G. Layer-by-layer assembly of antibacterial composite coating for leather with cross-link enhanced durability against laundry and abrasion. Appl Surf Sci. 2018;458:978-87.

9. Shi $\mathrm{H}$, Chen $Y$, Fan $H$, Xiang J, Shi B. Thermosensitive polyurethane film and finished leather with controllable water vapor permeability. J Appl Polym Sci. 2010;117:1820-7.

10. Mohamed OA, Abdel-Mohdy FA. Preparation of flame-retardant leather pretreated with pyrovatex CP. J Appl Polym Sci. 2006;99:2039-43.

11. Fan $\mathrm{H}, \mathrm{Gao} \mathrm{L}$, Wang Q. Research on the application of nanometer $\mathrm{TiO}_{2}$ in the leather industry. Leather Chem. 2011;28:22-5. (in Chinese).

12. Wang T, Bao Y. Advances on functional polyacrylate/inorganic nanocomposite latex for leather finishing. Mater Rev. 2017;31:64-71 (in Chinese).

13. Velmurugan $\mathrm{P}$, Cho M, Lee SM, Park JH, Bae S, Oh BT. Antimicrobial fabrication of cotton fabric and leather using green-synthesized nanosilver. Carbohydr Polym. 2014;106:319-25.

14. Yu Y, Liao B, Li G, Jiang S, Su F. Synthesis and properties of photosensitive silicone-containing polyurethane acrylate for leather finishing agent. Ind Eng Chem Res. 2014:53:564-71.

15. Qu J, Li Y, Chen H. Development of aqueous polyurethane finishing agent. Leather Chem. 2001;1:6-10. (in Chinese).

16. Chai S, Zhang Z. Comparison of finishing application for aliphatic polyurethane dispersions and polyurethane/polyacrylate composite emulsions. J Am Leather Chem Assoc. 2010;105:41-50.

17. Xu H, Ning H, Chen Y, Fan H, Shi B. Sulfanilamide-conjugated polyurethane coating with enzymatically-switchable antimicrobial capability for leather finishing. Prog Org Coat. 2013;76:924-34.

18. Xie C. Synthesis and application of a reactive polyurethane emulsion for leather finishing. Leather Sci Eng. 1992;3:003 (in Chinese).

19. Ma J, Xu Q, Gao D, Zhou J, Zhang J. Blend composites of caprolactammodified casein and waterborne polyurethane for film-forming binder: miscibility, morphology and properties. Polym Degrad Stab. 2012:97:1545-52

20. Novak BM. Hybrid nanocomposite materials-between inorganic glasses and organic polymers. Adv Mater. 1993:5:422-33.

21. Beecroft LL, Ober CK. Nanocomposite materials for optical applications. Chem Mater. 1997:9:1302-17.

22. Avella M, Vlieger JJD, Errico ME, Fischer S, Vacca P, Volpe MG. Biodegradable starch/clay nanocomposite films for food packaging applications. Food Chem. 2005;93:467-74

23. Wu Y, Liu X, Cui J, Meng M, Dai J, Li C, Yan Y. Bioinspired synthesis of highperformance nanocomposite imprinted membrane by a polydopamineassisted metal-organic method. J Hazard Mater. 2017;323:663-73.

24. Kaygusuz MK, Meyer M, Aslan A. The effect of $\mathrm{TiO}_{2}-\mathrm{SiO}_{2}$ nanocomposite on the performance characteristics of leather. Mater Res. 2017;20:1103-10.

25. Q. Zhou. Study on its application of acrylic resin modified by nano-TiO powder in leather finishing. Master diss. Weiyang district, Xi'an: Shaanxi University of Science \& Technology, 2005. (in Chinese).

26. Zhang Z, Ma J, Hu J, Zhang X. Study of the in-situ preparation of nano $\mathrm{SiO}_{2} /$ acrylic resin leather coating agent. Fine Chem. 2006;23:1113-7 (in Chinese).

27. Wang Y, Ma J, Xu Q, Zhang J. Fabrication of antibacterial casein-based ZnO nanocomposite for flexible coatings. Mater Des. 2017;113:240-5.

28. Xu Q, Ma J, Zhou J, Wang Y, Zhang J. Bio-based core-shell casein-based silica nano-composite latex by double-in situ polymerization: synthesis, characterization and mechanism. Chem Eng J. 2013;228:281-9.

29. Xu Q, Fan Q, Ma J, Yan Z. Facile synthesis of casein-based $\mathrm{TiO}_{2}$ nanocomposite for self-cleaning and high covering coatings: insights from $\mathrm{TiO}_{2}$ dosage. Prog Org Coat. 2016;99:223-9.

30. Wang B, Wilkes GL, Hedrick JC, Liptak SC, McGrath JE. New high-refractiveindex organic/inorganic hybrid materials from sol-gel processing. Macromolecules. 1991;24:3449-50.

31. Schubert U, Huesing $N$, Lorenz A. Hybrid inorganic-organic materials by solgel processing of organofunctional metal alkoxides. Chem Mater. 1995;7: 2010-27.

32. Amerio E, Sangermano M, Malucelli G, Priola A, Voit B. Preparation and characterization of hybrid nanocomposite coatings by photopolymerization and sol-gel process. Polymer. 2005;46:11241-6.

33. Wang $X$, Xing $W$, Song $L$, Yang $H, H u$ Y, Yeoh GH. Fabrication and characterization of graphene-reinforced waterborne polyurethane 
nanocomposite coatings by the sol-gel method. Surf Coat Technol. 2012; 206:4778-84.

34. Ma J, Hu J, Yang ZS, Liu L. Preparation of acrylic resin/modified nano-SiO 2 via solgel method for leather finishing agent. J Sol-Gel Sci Technol. 2007;41:209-16.

35. Kango S, Kalia S, Celli A, Njuguna J, Habibi Y, Kumar R. Surface modification of inorganic nanoparticles for development of organic-inorganic nanocomposites-a review. Prog Polym Sci. 2013;38:1232-61.

36. Song N, Hou X, Cui S, Ba C, Jiao D, Ding P, Shi L. Polycarbonate composites: effect of filler type and melt-blending process on the light diffusion properties. Polym Eng Sci. 2017;57:374-80.

37. Abbasian M, Pakzad M, Amirmanesh M. Polymericaly modified clays to preparation of polystyrene nanocomposite by nitroxide mediated radical polymerization and solution blending methods. Polym Compos. 2017;38:1127-34.

38. Zhang SW, Zhou SX, Weng YM, Wu LM. Synthesis of $\mathrm{SiO}_{2} /$ polystyrene nanocomposite particles via miniemulsion polymerization. Langmuir. 2005; 21:2124-8.

39. Jai C, Lv S, Ding H. Research on graphene oxide modified waterborne polyurethane leather finishing. West Leather. 2016;38:40-6 (in Chinese).

40. Lai S, Jin Y, Shi L, Sun X. Application of carboxylated graphene oxide in modification of polyacrylate leather finishing agent. Leather Sci Eng. 2017; 27:17-23 53. (in Chinese).

41. Wang $Q$, Zhu F, Sun G, Zhou Q. Study of acrylic resin finishing agent modified by blending nano- $\mathrm{TiO}_{2}$. China Leather. 2007:36:9-12 17. (in (hinese).

42. Zhang W, Ma J, Gao D, Zhou Y, Li C, Zha J, Zhang J. Preparation of aminofunctionalized graphene oxide by Hoffman rearrangement and its performances on polyacrylate coating latex. Prog Org Coat. 2016;94:9-17.

43. Goyal A, Kumar A, Patra PK, Mahendra S, Tabatabaei S, Alvarez PJJ, John G, Ajayan PM. In situ synthesis of metal nanoparticle embedded free standing multifunctional PDMS films. Macromol Rapid Commun. 2009;30:1116-22.

44. Lu Z, Xiao J, Wang Y, Meng M. In situ synthesis of silver nanoparticles uniformly distributed on polydopamine-coated silk fibers for antibacterial application. J Colloid Interface Sci. 2015;452:8-14.

45. Avella M, Errico ME, Martuscelli E. Novel PMMA/ $\mathrm{CaCO}_{3}$ nanocomposites abrasion resistant prepared by an in situ polymerization process. Nano Lett. 2001;1:213-7.

46. Kim S, Fornasiero F, Park HG, In JB, Meshot E, Giraldo G, Stadermann M, Fireman M, Shan J, Grigoropoulos CP, Bakajin O. Fabrication of flexible, aligned carbon nanotube/polymer composite membranes by in-situ polymerization. J Membr Sci. 2014;460:91-8.

47. Liu J, Ma J, Bao Y, Wang J, Zhu Z, Tang H, Zhang L. Nanoparticle morphology and film-forming behavior of polyacrylate/ZnO nanocomposite. Compos Sci Technol. 2014;98:64-71.

48. Chen W, Feng L, Qu B. In situ synthesis of poly (methyl methacrylate)/MgAl layered double hydroxide nanocomposite with high transparency and enhanced thermal properties. Solid State Commun. 2004;130:259-63.

49. Bao Y, Shi C, Ma J, Wang B, Zhang Y. Double in-situ synthesis of polyacrylate/nano-TiO 2 composite latex. Prog Org Coat. 2015;85:101-8

50. Gaidau C, Petica A, Ignat M, lordache O, Ditu L, lonescu M. Enhanced photocatalysts based on ag- $-\mathrm{TiO}_{2}$ and ag- $-\mathrm{N}-\mathrm{TiO}_{2}$ nanoparticles for multifunctional leather surface coating. Open Chem. 2016;14:383-92.

51. Liu J, Ma J, Bao Y, Wang J, Tang H, Zhang L. Polyacrylate/surface-modified $\mathrm{ZnO}$ nanocomposite as film-forming agent for leather finishing. Int J Polym Mater Polym Biomater. 2014;63:809-14.

52. Bao Y, Feng C, Wang C, Ma J, Tian C. Hygienic, antibacterial, UV-shielding performance of polyacrylate/ZnO composite coatings on a leather matrix. Colloids Surf A Physicochem Eng Asp. 2017;518:232-40

53. Jing $\mathrm{H}, \mathrm{Ma}$ J, Deng W. Properties of acrylic resin/nano- $\mathrm{SiO}_{2}$ leather finishing agent prepared via emulsifier-free emulsion polymerization. Mater Lett. 2008:62:2931-4.

54. Liu J, Ma J, Bao Y, Zhu Z. Synthesis and application of polyacrylate/nano$\mathrm{SiO}_{2}$ composite leather finishing agent with polymerizable surfactant. Polym-Plast Technol Eng. 2012;51:1460-7.

55. Liu J, Ma J, Bao Y, Zhu Z, Zhang J, Ma Y. Effect of long-chain acrylate on the properties of polyacrylate/nano-SiO ${ }_{2}$ composite leather finishing agent. Polym-Plast Technol Eng. 2011;50:1546-51.

56. Ma J, Zhang X, Bao Y, Liu J. A facile spraying method for fabricating superhydrophobic leather coating. Colloids Surf A Physicochem Eng Asp. 2015;472:21-5

57. Petica A, Gaidau C, Ignat M, Sendrea C, Anicai L. Doped $\mathrm{TiO}_{2}$ nanophotocatalysts for leather surface finishing with self-cleaning properties. J Coat Technol Res. 2015;12:1153-63.
58. Gaidau C, Petica A, Ignat M, Popescu LM, Piticescu RM, Tudor IA. Preparation of silica doped titania nanoparticles with thermal stability and photocatalytic properties and their application for leather surface functionalization. Arab J Chem. 2017:10:985-1000.

59. Bao Y, Yang Y, Ma J. Fabrication of monodisperse hollow silica spheres and effect on water vapor permeability of polyacrylate membrane. J Colloid Interface Sci. 2013;407:155-63.

60. Bao Y, Yang Y, Shi C, Ma J. Fabrication of hollow silica spheres and their application in polyacrylate film forming agent. J Mater Sci. 2014;49:8215-25.

61. Wang T, Bao Y. Advances on functional polyacrylate/inorganic nanocomposite latex. Mater Rev. 2017;3:64-71 (in Chinese).

62. Fan Q, Ma J, Xu Q, Wang J, Ma Y. Facile synthesis of chitosan-coated silica nanocapsules via interfacial condensation approach for sustained release of vanillin. Ind Eng Chem Res. 2018;57:6171-9.

63. Fan $\mathrm{Q}, \mathrm{Ma} J, \mathrm{Xu} \mathrm{Q}$. Facile synthesis of chitosan-based silica nanocapsules for fragrance-controlled release leather finishes. XXXIII IULTCS congress proceedings, India; 2017

64. Zhang F, Ma J, Xu Q, Zhou J, Simion D, Carmen G. A facile method for fabricating room-temperature-film-formable casein-based hollow nanospheres. Colloids Surf A Physicochem Eng Asp. 2015;484:329-35.

65. Fan Q, Ma J, Xu Q, An W, Qiu R. Multifunctional coatings crafted via layerby-layer spraying method. Prog Org Coat. 2018;125:215-21.

\section{Submit your manuscript to a SpringerOpen ${ }^{\circ}$ journal and benefit from:}

- Convenient online submission

- Rigorous peer review

- Open access: articles freely available online

- High visibility within the field

- Retaining the copyright to your article

Submit your next manuscript at $\boldsymbol{\nabla}$ springeropen.com 